\title{
Outcomes of Laparoscopic vs. Open Reversal of Hartmann's Procedure: A Single Centre Experience
}

\author{
Zehong Chen ${ }^{1}$, Nandu Nair ${ }^{2}$, Umar Hanif ${ }^{3}$
}

1. Trauma \& Orthopaedics, Sandwell General Hospital, Birmingham, GBR 2. General Surgery, Royal Stoke University Hospital, Stoke-on-Trent, GBR 3. Trauma and Orthopaedics, Northampton General Hospital, Northampton, GBR

Corresponding author: Zehong Chen, zehong.chen@nhs.net

\section{Abstract \\ Introduction}

Hartmann's procedure is widely performed to fix colonic obstruction and perforation. It should ideally be followed by a reversal to restore bowel continuity. Reversal of Hartmann's procedure was traditionally performed using an open technique. However, in recent days, the use of a laparoscopic approach has become increasingly popular. In our retrospective observational study, we aim to investigate the outcomes of laparoscopic versus open reversal of Hartmann's procedure in a UK tertiary centre.

\section{Methods}

All patients who underwent reversal of their Hartmann's procedure between January 2017 and December 2019 were included in the study. Data including demographics, days between primary operation and reversal, laparoscopic or open reversal, length of hospital stay following reversal procedure, 30-day readmission, mortality, and complication rate were collected. Statistical analysis was performed using t-test and chi-squared test.

\section{Results}

Forty-nine patients underwent reversal of Hartmann's procedure from January 2017 to December 2019. The mean age of our cohort was $59.6 \pm 13.2$ years. There was no significant difference in baseline demographics of both groups, apart from the number of days between the primary operation and reversal procedure. There was also no statistical difference in length of stay, 30-day readmission, and mortality between laparoscopic and open reversal techniques. However, there was a higher incidence of wound complications in patients who underwent open reversal of Hartmann's procedure.

\section{Conclusion}

Review began 07/29/2021 Review ended 08/04/2021 Published 08/17/2021

\section{() Copyright 2021}

Chen et al. This is an open access article distributed under the terms of the Creative Commons Attribution License CC-BY 4.0., which permits unrestricted use, distribution, and reproduction in any medium, provided the original author and source are credited.
The reversal of Hartmann's procedure is a challenging operation. We found no significant difference between both open and laparoscopic approaches, but our study might be confounded by various factors including small sample size and selection bias. A larger, randomised study with greater statistical power is needed to confirm our findings.

\footnotetext{
Categories: General Surgery

Keywords: hartmann procedure, reversal of hartmann's procedure, laparoscopic reversal hartmann's procedure, colostomy, minimally invasive laparoscopy
}

\section{Introduction}

Hartmann's procedure was first described by Henri Hartmann in 1921, as a novel approach in response to high rates of complications and mortality following resection and primary anastomosis of left-sided colonic obstruction [1]. One century later, this procedure is still widely performed to fix colonic obstruction and perforation in patients, both in elective and emergency settings. Hartmann's procedure involves resection of the rectosigmoid colon, closure of the rectal stump, and creation of an end colostomy. Over the years, indications for the procedure have grown to cover a wide range of abdominal pathologies including colonic malignancy, diverticulitis, ischemia, and volvulus [2].

Hartmann's procedure should ideally be followed by a reversal to restore bowel continuity. Reversal of Hartmann's procedure involves the closure of a left-sided colostomy and anastomosis of a proximal colon and distal rectal stump. Patients with successful reversal of Hartmann's procedure often report better quality of life, as they no longer need to manage the physical and psychological challenges associated with a stoma [3]. Despite the benefits of reversal of Hartmann's procedure, many patients do not proceed with it and instead, remain with a permanent colostomy. This is due to a variety of reasons including high rates of post-operative complications such as chronic infection, adhesion, anastomotic leak, technical challenges 
during the reversal such as difficulty in identification of and anastomosis to a short rectal stump, patient's comorbid status limiting further surgery and patient's preference $[4,5]$. With these considerations, patients are often carefully selected for the reversal procedure and less than half of all patients who undergo a Hartmann's procedure will end up having a reversal [6]. The United Kingdom (UK) National Bowel Cancer Audit in 2019 reported that $89.7 \%$ of patients who underwent Hartmann's procedure still had a stoma at 18 months postoperatively [7].

Reversal of Hartmann's procedure was conventionally performed using an open technique. In recent days, laparoscopy has become increasingly popular due to its benefits in postoperative recovery and surgical outcomes [8,9]. In our retrospective observational study, we aimed to investigate the outcomes of laparoscopic versus open reversal of Hartmann's procedure in a UK tertiary centre.

\section{Materials And Methods \\ Data collection}

All patients who underwent reversal of their Hartmann's procedure in our hospital between January 2017 and December 2019 were included in the study. Patients who did not have all of their parameters recorded in the hospital electronic database were excluded from the study.

\section{Variables}

The following parameters were recorded for all patients: age, gender, American Society of Anaesthesiologist (ASA) grade, co-morbidities, number of days between primary operation and reversal of Hartmann's procedure, laparoscopic or open reversal, length of hospital stay following reversal procedure, 30-day readmission, mortality, and complication rate. Two independent authors corroborated data collection.

\section{Outcomes}

Our primary outcomes were 30-day readmission and 30-day mortality rates. The secondary outcome was the length of hospital stay.

\section{Statistical analysis}

All analyses were intention-to-treat, hence patients whose laparoscopic reversal of Hartmann's were converted to open were analysed in the laparoscopic arm. Statistical analysis was performed using GraphPad Prism version 9.1.2 (GraphPad Software, San Diego, CA, USA). Continuous data are presented as mean \pm standard deviation and analysed using a t-test. Categorical data are presented as numbers and percentages and analysed using a chi-squared test. Data was considered statistically significant when $\mathrm{p}<0.05$.

\section{Results}

Forty-nine patients underwent reversal of Hartmann's procedure from January 2017 to December 2019. Patients were routinely followed-up but duration of follow-up was not analysed as part of the study. The mean age of our cohort was $59.6 \pm 13.2$ years. $53 \%$ of patients were males. The most common indication for Hartmann's surgery was complicated diverticulitis (51\%) followed by colorectal cancer (27\%). Twenty-seven patients (55\%) underwent an open reversal while 22 patients (45\%) had a laparoscopic reversal. Of the latter, nine patients $(41 \%)$ required conversion to an open reversal.

There was no statistical difference in baseline demographics of both groups, apart from the number of days between the primary operation and reversal procedure. The average duration between the initial Hartmann's surgery and laparoscopic reversal was $682 \pm 446.3$ days, compared to $447 \pm 269.5$ days in the open reversal group $(\mathrm{p}=0.04)$. Baseline characteristics are presented in Table 1 . 


\section{Cureus}

\begin{tabular}{|c|c|c|c|}
\hline Characteristic & Laparoscopic reversal $n=22(\%)$ & Open reversal n=27 (\%) & P-value \\
\hline Age (years) & $58.8 \pm 13.4$ & $60.1 \pm 13.3$ & 0.73 \\
\hline Gender, male & $13(59)$ & $13(48)$ & 0.57 \\
\hline \multicolumn{4}{|c|}{ Indication for Hartmann's procedure } \\
\hline Colon cancer & $8(36)$ & $5(19)$ & \\
\hline Diverticulitis complication & $10(45)$ & $15(56)$ & \\
\hline Perforation & $1(5)$ & $2(7)$ & \\
\hline Trauma & 0 & $2(7)$ & \\
\hline Others & $3(14)$ & $3(11)$ & \\
\hline Open Hartmann's procedure & $15(68)$ & $22(81)$ & \\
\hline Mean ASA score & 2.1 & 2.1 & 0.73 \\
\hline \multicolumn{4}{|l|}{ ASA score } \\
\hline 1 & $2(9)$ & $3(11)$ & \\
\hline 2 & $15(68)$ & $16(59)$ & \\
\hline 3 & $5(23)$ & $8(30)$ & \\
\hline \multicolumn{4}{|l|}{ Co-morbidity } \\
\hline Diabetes & $6(27)$ & $2(7)$ & 0.12 \\
\hline Ischaemic heart disease & $2(9)$ & $6(22)$ & 0.27 \\
\hline Hypertension & $6(27)$ & $9(33)$ & 0.55 \\
\hline Days between operation & $682.4 \pm 446.3$ & $444.7 \pm 269.5$ & 0.04 \\
\hline Conversion to open & $9(41)$ & - & \\
\hline
\end{tabular}

TABLE 1: Baseline characteristics of patients undergoing reversal of Hartmann's procedure

There was no statistical difference in short-term outcomes of laparoscopic or open reversal (Table 2). Five patients from each group were readmitted to hospital within 30 days. Complications requiring readmission in the laparoscopic reversal group included high output ileostomy, intra-abdominal collection and retained sutures. Complications in the open reversal group requiring readmission included anastomotic leak, renal failure due to high output ileostomy and three incidences of wound complications. There was no mortality within 30 days.

\begin{tabular}{|c|c|c|c|}
\hline Characteristic & Laparoscopic reversal $n=22(\%)$ & Open reversal $\mathrm{n}=27$ (\%) & P-value \\
\hline 30 day re-admission & $5(23)$ & $5(19)$ & 0.74 \\
\hline 30 day mortality & 0 & 0 & - \\
\hline Length of hospital stay (days) & $10.2 \pm 7.6$ & $11.7 \pm 9.9$ & 0.45 \\
\hline
\end{tabular}

TABLE 2: Short-term outcomes in patients undergoing reversal of Hartmann's procedure

\section{Discussion}

\section{Duration between primary Hartmann's procedure and reversal}

There is no clear consensus with regard to the optimal time for reversal of Hartmann's procedure. In the existing literature, the average duration for reversal is seven to eight months after the primary Hartmann's 
procedure [10-13]. Contrastingly, our study reported an average duration of 22 months for laparoscopic reversal and 14 months for an open procedure.

Delayed reversal has been shown to optimise clinical and nutritional states of patients prior to their reversal procedure, and enable resolution of the underlying pathology, besides providing time for adhesion and scar tissues to mature $[14,15]$. However, prolonged duration to reversal is also associated with increased complications such as atrophy of the distal stump and difficulty locating it during surgery $[16,17]$.

It is important to note that an element of selection bias might be introduced in these studies, as surgeons who anticipated challenging reversals might delay the operation for various reasons, including optimising the patient pre-operatively. Additionally, early reversal might not be an option in patients who underwent Hartmann's procedure for malignancy due to the administration of adjuvant chemoradiotherapy. These patients tend to have a longer interval before consideration of reversal, and a reversal is often performed via an open approach. $27 \%$ of our patients had their index Hartmann's procedure due to colon cancer, which might contribute to our protracted interval to reversal.

\section{Conversion from laparoscopic to open reversal}

Laparoscopic reversal of Hartmann's procedure is one of the most technically challenging operations in colorectal surgery, and high conversion rates to open surgery have been reported [18]. Our study found a conversion rate of $41 \%$, which is significantly higher than the reported average of $16 \%$, but within the range of $0-50 \%[19]$.

Various reasons could contribute to a laparoscopic reversal being converted to open; the most common being multiple adhesions, small pelvic workspace, and inability to identify, or injury to the rectal stump.

Chouillard et al. also found that the conversion rate to an open reversal was lower if the primary Hartmann's procedure was performed laparoscopically [20]. This could expound our high conversion rate, as seven out of nine patients (78\%) who underwent conversion had an index open Hartmann's procedure.

\section{Complications}

Laparoscopic reversal of Hartmann's procedure is a technically difficult operation but has been reported to carry benefits such as decreased complication and mortality rates $[8,9]$. In our cohort of patients, there was no short-term mortality. There were five cases of 30-day readmission in each group, with an increase in wound complications $(11 \%)$ in patients who underwent an open reversal. This was again consistent with published literature, which reported higher events of wound complications in patients who underwent open reversal of Hartmann's procedure $[21,22]$.

\section{Outcome measures}

Similar to existing literature, there was no statistical difference in our 30-day readmission and 30-day mortality rates between both groups. Our 30-day mortality rate was also comparable to that of existing literature [23-26]. Contrary to Siddiqui, Yang, and Morgan, laparoscopic reversal did not reduce the length of hospital stay $[26,27]$.

\section{Limitations}

There are several limitations to our study, namely its retrospective nature and our small sample size. The small cohort and low volume of Hartmann's reversal performed in our centre limited our statistical power and might explain why we were not able to demonstrate statistical effects in our cohort. Selection bias could also be introduced, as the patients and surgeons jointly decided on the surgical approach. Other factors that possibly confounded our study included patient variables such as nutritional status and the variation in laparoscopic technical skills among surgeons, who were at different points of their learning curves.

\section{Conclusions}

Reversal of Hartmann's procedure is a challenging operation, and its success is dependent on patient factors and surgeon expertise. There was no significant difference in outcomes between laparoscopic and open reversal of Hartmann's procedure, although there was a higher incidence of wound complications in patients who underwent open reversal of Hartmann's procedure. When considering the appropriate approach for reversal of Hartmann's procedure, surgeons should take into account patient factors such as preference and co-morbidities, and surgeon factors such as prior training and laparoscopic skills. As our study might be confounded by various factors including small sample size and selection bias, a larger, randomised study with greater statistical power is needed to confirm our findings.

\section{Additional Information \\ Disclosures}

Human subjects: Consent was obtained or waived by all participants in this study. Animal subjects: All 
authors have confirmed that this study did not involve animal subjects or tissue. Conflicts of interest: In compliance with the ICMJE uniform disclosure form, all authors declare the following: Payment/services info: All authors have declared that no financial support was received from any organization for the submitted work. Financial relationships: All authors have declared that they have no financial relationships at present or within the previous three years with any organizations that might have an interest in the submitted work. Other relationships: All authors have declared that there are no other relationships or activities that could appear to have influenced the submitted work.

\section{Acknowledgements}

The authors appreciate the help of Mr Sudipta Roy, Consultant General Surgeon in Royal Stoke University Hospital, who offered valuable advice.

\section{References}

1. Sanderson ER: Henri Hartmann and the Hartmann operation . Arch Surg. 1980, 115:792-3. 10.1001/archsurg.1980.01380060088026

2. Barbieux J, Plumereau F, Hamy A: Current indications for the Hartmann procedure. J Visc Surg. 2016, 153:31-8. 10.1016/j.jviscsurg.2016.01.002

3. Vermeulen J, Gosselink MP, Busschbach JJ, Lange JF: Avoiding or reversing Hartmann's procedure provides improved quality of life after perforated diverticulitis. J Gastrointest Surg. 2010, 14:651-7. 10.1007/s11605010-1155-5

4. Aydin HN, Remzi FH, Tekkis PP, Fazio VW: Hartmann's reversal is associated with high postoperative adverse events. Dis Colon Rectum. 2005, 48:2117-26. 10.1007/s10350-005-0168-8

5. Lucchetta A, De Manzini N: Laparoscopic reversal of Hartmann procedure: is it safe and feasible? . Updates Surg. 2016, 68:105-10. 10.1007/s13304-016-0363-2

6. Hallam S, Mothe BS, Tirumulaju R: Hartmann's procedure, reversal and rate of stoma-free survival . Ann R Coll Surg Engl. 2018, 100:301-7. 10.1308/rcsann.2018.0006

7. National bowel cancer audit annual report 2019. (2020). Accessed: July 7, 2021: http://www.nboca.org.uk/content/uploads/2020/01/NBOCA-2019-V2.0.pdf.

8. Braga M, Vignali A, Gianotti L, et al.: Laparoscopic versus open colorectal surgery: a randomized trial on short-term outcome. Ann Surg. 2002, 236:759-66.

9. Braga M, Frasson M, Vignali A, Zuliani W, Civelli V, Di Carlo V: Laparoscopic vs. open colectomy in cancer patients: long-term complications, quality of life, and survival. Dis Colon Rectum. 2005, 48:2217-23. 10.1007/s10350-005-0185-7

10. Horesh N, Lessing Y, Rudnicki Y, et al.: Timing of colostomy reversal following Hartmann's procedure for perforated diverticulitis. J Visc Surg. 2020, 157:395-400. 10.1016/j.jviscsurg.2020.01.005

11. Fleming FJ, Gillen P: Reversal of Hartmann's procedure following acute diverticulitis: is timing everything? . Int J Colorectal Dis. 2009, 24:1219-25. 10.1007/s00384-009-0747-6

12. Ghorra SG, Rzeczycki TP, Natarajan R, Pricolo VE: Colostomy closure: impact of preoperative risk factors on morbidity. Am Surg. 1999, 65:266-9.

13. Bielecki K, Kamiński P: Hartmann procedure: place in surgery and what after? . Int J Colorectal Dis. 1995, 10:49-52. 10.1007/BF00337588

14. Banerjee S, Leather AJ, Rennie JA, Samano N, Gonzalez JG, Papagrigoriadis S: Feasibility and morbidity of reversal of Hartmann's. Colorectal Dis. 2005, 7:454-9. 10.1111/j.1463-1318.2005.00862.x

15. Pearce NW, Scott SD, Karran SJ: Timing and method of reversal of Hartmann's procedure . Br J Surg. 1992, 79:839-41. 10.1002/bjs.1800790844

16. Roque-Castellano C, Marchena-Gomez J, Hemmersbach-Miller M, Acosta-Merida A, Rodriguez-Mendez A, Fariña-Castro R, Hernandez-Romero J: Analysis of the factors related to the decision of restoring intestinal continuity after Hartmann's procedure. Int J Colorectal Dis. 2007, 22:1091-6. 10.1007/s00384-007-0272-4

17. Tan WS, Lim JF, Tang CL, Eu KW: Reversal of Hartmann's procedure: experience in an Asian population . Singapore Med J. 2012, 53:46-51.

18. Jamali FR, Soweid AM, Dimassi H, Bailey C, Leroy J, Marescaux J: Evaluating the degree of difficulty of laparoscopic colorectal surgery. Arch Surg. 2008, 143:762-8. 10.1001/archsurg.143.8.762

19. Celentano V, Giglio MC, Bucci L: Laparoscopic versus open Hartmann's reversal: a systematic review and meta-analysis. Int J Colorectal Dis. 2015, 30:1603-15. 10.1007/s00384-015-2325-4

20. Chouillard E, Pierard T, Campbell R, Tabary N: Laparoscopically assisted Hartman's reversal is an efficacious and efficient procedure: a case control study. Minerva Chir. 2009, 64:1-8.

21. Clermonts SH, de Ruijter WM, van Loon YT, Wasowicz DK, Heisterkamp J, Maring JK, Zimmerman DD: Reversal of Hartmann's procedure utilizing single-port laparoscopy: an attractive alternative to laparotomy . Surg Endosc. 2016, 30:1894-901. 10.1007/s00464-015-4407-3

22. Poon JT, Law WL, Wong IW, Ching PT, Wong LM, Fan JK, Lo OS: Impact of laparoscopic colorectal resection on surgical site infection. Ann Surg. 2009, 249:77-81. 10.1097/SLA.0b013e31819279e3

23. Brathwaite S, Kuhrt M, Yu L, Arnold M, Husain S, Harzman AE: Retrospective evaluation of laparoscopic versus open hartmann's reversal: a single-institution experience. Surg Laparosc Endosc Percutan Tech. 2015, 25:e156-8. 10.1097/SLE.0000000000000201

24. Melkonian E, Heine C, Contreras D, et al.: Reversal of the Hartmann's procedure: a comparative study of laparoscopic versus open surgery. J Minim Access Surg. 2017, 13:47-50. 10.4103/0972-9941.181329

25. Zimmermann M, Hoffmann M, Laubert $\mathrm{T}$, et al.: Laparoscopic versus open reversal of a Hartmann procedure: a single-center study. World J Surg. 2014, 38:2145-52. 10.1007/s00268-014-2507-1

26. Yang PF, Morgan MJ: Laparoscopic versus open reversal of Hartmann's procedure: a retrospective review . ANZ J Surg. 2014, 84:965-9. 10.1111/ans.12667

27. Siddiqui MR, Sajid MS, Baig MK: Open vs laparoscopic approach for reversal of Hartmann's procedure: a 


\section{Cureus}

systematic review. Colorectal Dis. 2010, 12:733-41. 10.1111/j.1463-1318.2009.01892.x 